\title{
Wheat yield estimation using remote sensing and the STICS model in the semiarid Yaqui valley, Mexico
}

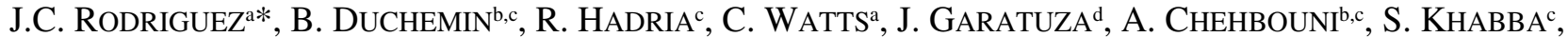 \\ G. BOULET ${ }^{\mathrm{b}, \mathrm{c}}$, E. PALACIOS ${ }^{\mathrm{e}}$, A. LAHROUNI ${ }^{\mathrm{c}}$ \\ a IMADES, Instituto del Medio Ambiente y Desarrollo Sustentable, Hermosillo, Mexico \\ ${ }^{b}$ CESBIO, Centre D'Études Spatiales de la Biosphere CESBIO, Toulouse, France \\ ${ }^{\mathrm{c}}$ FSSM, Faculté des Sciences Semlalia, Marrakech, Morocco \\ d ITSON, Instituto Tecnologico de Sonora, Cd. Obregon, Mexico \\ ${ }^{\mathrm{e}}$ COLPOS, Colegio de Postgraduados, Montecillo, Mexico
}

(Received 17 June 2003; accepted 8 September 2003)

\begin{abstract}
During the 1999/2000 agricultural seasons, an experiment was carried out on winter wheat fields in the semiarid Yaqui Valley (Northwest Mexico). This data set was used to calibrate the evolution of the leaf area index (LAI) simulated by STICS, which was found to be in excellent agreement with estimates obtained from field reflectance measurements. After calibration, STICS was able to simulate satisfactorily the seasonal levels and trends observed in net radiation, soil moisture and evapotranspiration, but the crop temperature was overestimated by about $2.5^{\circ} \mathrm{C}$. On a larger scale, STICS was run on 16 fields with contrasting management practices. The simulations indicate that yield predictability is significantly lower for later sowing dates, consistent with observations. The seasonal variations of field and satellite data (Landsat-ETM+, Terra-MODIS and VEGETATION) NDVI were very close. However, some difficulties were noted: saturation of NDVI at high LAI values and smoothed variability on a 1-km spatial scale, as well as the need for a sound methodology for processing satellite data.
\end{abstract}

crop model / STICS / calibration / winter wheat / LAI / reflectance / NDVI / remote sensing

\section{INTRODUCTION}

Remote sensing and vegetation models are very important tools for monitoring crop growth and for providing yield assessment. Remote-sensing data in the visible, near- and thermal infrared spectral bands have been used to monitor the phenology $[13,36]$ and infer canopy biophysical variables such as leaf area index (LAI), vegetation coverage, fraction of photosynthetically active radiation, surface temperature, crop coefficients, yield and biomass in different ecosystems $[5,11,16$, 28, 29].

Many crop models have been designed to understand the relations between soil, plant and atmosphere and to predict biomass components and grain yield. At the moment there are models for particular crops (e.g. CERES-Wheat [30]) as well as generic models for several crops or plants that can even run sequences through years (e.g. STICS [8-10], DSSAT [19] and APSIM [27]). Many of these models place special emphasis on the plant water, nitrogen or carbon balance, since they have been designed for particular applications under specific climate conditions [7]. The advantage of STICS is that it was designed with such things as remote sensing in mind.
Remote sensing has been used in different parts of the world to estimate crop yield. Remotely-sensed estimates can be based on vegetation indices (VIs) using simple regression against LAI or the fraction of photosynthetically active radiation $[24,32]$. These show good agreement with harvest data, provided VIs are obtained when the vegetation cover is high. This estimation technique is quite economical given the relatively low price nowadays of satellite imagery. However, it requires local calibration. Crop models using climatic and agronomic data also give good correlation between model prediction and harvest data on local scales [18]. They simulate key variables such as LAI, which can be used to link model simulations to remotelysensed data. Several methods have been proposed for estimating LAI from reflectances observed by remote sensors. These include the use of radiative transfer models in conjunction with an inversion scheme [23] and the derivation from relationships between LAI and vegetation indices [2,3]. Consequently, it should be possible to improve the spatial estimation of yield (and associated variables such as water and nitrogen balance) by combining crop models and satellite observations.

The results obtained on a regional scale generally show good agreement with field measurements [24, 32]. However, a persistent

* Corresponding authors: jcrod@imades.org 


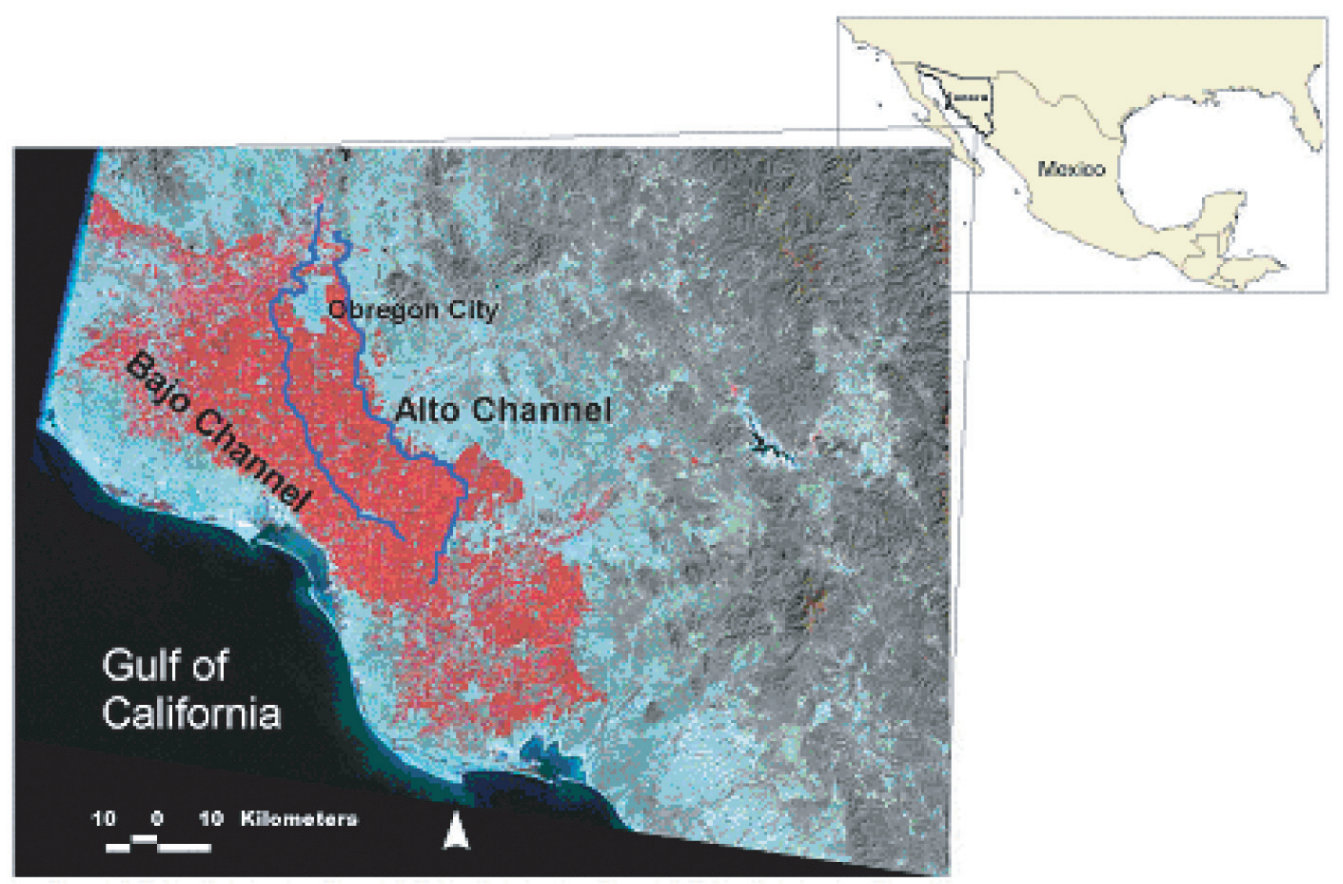

Figure 1. The Yaqui Valley (Northwest Mexico) as observed by Landsat ETM+ (false colour composite, 4,3,2 channels) February 26, 2000.

problem for this approach has been the spatial resolution and frequency of satellite data. Currently no satellite system exists which provides high spatial and temporal resolution simultaneously (i.e. better than 30 metres available every day or so). This situation has been improved for agricultural areas with large fields by the MODerate resolution Imaging Spectroradiometer (MODIS), which provides a two-band (red and nearinfrared) product at 250-m resolution every two days. However, a totally satisfactory solution, which is also applicable to areas with small fields, will require new systems such as the RHEA proposal, which would provide daily data at 20-m resolution with 8 spectral bands (from blue to near-infrared) and a swath of $120 \mathrm{~km}$ [12].

In this context, the aim of this research is, firstly, to calibrate and validate the STICS model on the local scale in a semiarid environment and, secondly, to test the potential of using the model with ground-based reflectance measurements for the prediction of the spatial distribution of wheat yield in the valley of Yaqui (Sonora, Northwest Mexico) using an experimental data set collected on two wheat fields during the year 19992000. Satellite images were also acquired on different spatial scales from the Landsat-ETM+, VEGETATION and TerraMODIS sensors in order to make a preliminary evaluation of their potential.

\section{MATERIALS AND METHODS}

\subsection{Site description}

The Yaqui Valley is a large, flat agricultural area (the average slope is less than 1\%) in Northwest Mexico (Fig. 1). The area is irrigated with water from dams on the Yaqui river system, using a network of channels every $2 \mathrm{~km}$ that form blocks of 400 ha each (Fig. 2). The water is supplied by 2 large channels, each of which can transport up to $100 \mathrm{~m}^{3} \mathrm{~s}^{-1}$. The total irrigated surface is about 255000 ha and the main crop (occupying more than $50 \%$ of the area) is winter wheat which grows from November to April every year. The wheat is sown in the period from November 15 to December 31 . The soils in the valley are mostly deep and poor in organic matter $(<1 \%)$ and the principal types are clays and sandy clay, with sandy loam close to the river watercourses. The climate is semiarid with an annual rainfall of around $350 \mathrm{~mm}$. The rainy season is from July to September (with about $70 \%$ of the annual rainfall) and there is a very dry season with almost no rainfall from March to June. The mean daily temperature ranges from about $17^{\circ} \mathrm{C}$ in January to $31{ }^{\circ} \mathrm{C}$ in summer (July-August).

\subsection{Satellite data}

VEGETATION, Terra-MODIS and Landsat-7 ETM+ satellite images were collected during the experiment. The VEGETATION sensor acquires data in four optical spectral bands from $460 \mathrm{~nm}$ (blue) to $1670 \mathrm{~nm}$ (short-wave infrared), with a daily repeat rate, $\sim 1-\mathrm{km}$ pixel resolution and a $2250-\mathrm{km}$ swath. MODIS is a wide field-of-view sensor $(2330 \mathrm{~km})$ with a one- or two-day repeat rate, 36 spectral bands from $470 \mathrm{~nm}$ to $14240 \mathrm{~nm}$ and a variable spatial resolution of $250 \mathrm{~m}$ (two bands; red and infrared), $500 \mathrm{~m}$ ( 5 bands; visible, near-infrared and middle infrared) and $1000 \mathrm{~m}$ (29 bands; visible, near-infrared, middle infrared and thermal infrared). Landsat-ETM+ is high-resolution sensor with a 16-day repeat rate, 8 spectral bands at different spatial resolutions: $15 \mathrm{~m}$ (1 band; panchromatic), 

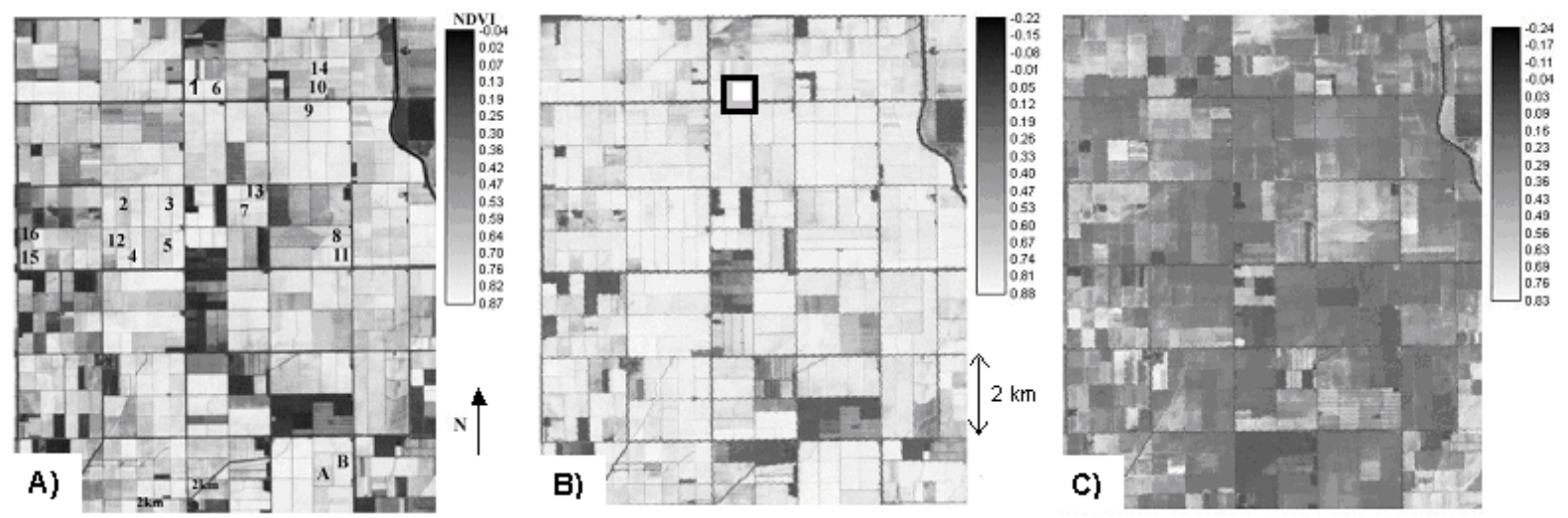

Figure 2. Sub-samples of NDVI images acquired by Landsat ETM+ on the Yaqui Valley at three dates during the 1999/2000 agricultural season: (A) January 25, (B) February 26 and (C) April 14. In Figure A, the numbers locate the fields with management practices and yield given in Table I; the letters show the main (A) and secondary (B) plots which were intensively monitored. At the top of Figure B, we have represented an example (field number 6) of one VEGETATION pixel (grey square) and the TM surface (white square) where the average NDVI value is extracted.

$30 \mathrm{~m}$ (6 bands; visible (3), near-infrared (1) and middle infrared (2)) and $60 \mathrm{~m}$ (1 band; thermal infrared) and a 180-km swath. VEGETATION S10 products are calibrated and corrected for atmospheric effects; 10-day composite data are obtained using the maximum value composite (MVC) technique [26]. Terra (the MODIS platform) was launched in 1999 and data were not available until March 2000. Five scenes (Level 1B two-band $250-\mathrm{m}$ product [20]), which calibrated and geolocated radiances were obtained at the end of the agricultural season. Three Landsat-ETM+ images were acquired during the agricultural season (January 25, February 26 and April 14, 2000; Fig. 2). These ETM+ and MODIS scenes were calibrated and converted to top-of-atmosphere reflectances, but no atmospheric corrections were performed.

All these images were geo-referenced and processed to obtain maps of the Normalised Difference Vegetation Index (NDVI). Then time series of mean NDVI were extracted for each field located in Figure 2A as follows: for ETM+ data, the fields are clearly identified and the average value of NDVI was computed for each field; for VEGETATION, the pixel that includes the field of interest is considered (see example in Fig. 2B for the field numbered 6). In other words, one or several pixels are associated with each NDVI value, according to the size of the field of interest and the spatial resolution of the sensor.

\subsection{Experimental data}

In the winter of 1999-2000, an experiment was carried out over a homogeneous surface of 20 ha (located in Fig. 2) of wheat that had been planted on December 10th. After emergence, different automatic sensors were installed on this main plot. The following variables were measured: net radiation components (CNR1, Kipp \& Zonen, Netherlands); latent and sensible heat fluxes (3D sonic anemometer CSAT3 and fast response hygrometer KH20, Campbell Scientific Inc., USA); soil heat flux, moisture and temperature at different depths (HFP3 plates, REBS Inc., USA; CS615 water content probes and 107 temperature probes, Campbell Scientific Inc., USA); air temperature and vapour pressure (HMP45C, Vaisala, Finland), and surface temperature (Everest thermoradiometer, Phoenix, USA). The raw data from the CSAT3 and KH20 were sampled at $20 \mathrm{~Hz}$ and stored on a $23 \times$ data logger (Campbell Scientific Inc., USA). The data were automatically downloaded every minute to a notebook computer for subsequent processing to produce 30-minute averages of latent and sensible heat fluxes. The program used was developed at Wageningen University in the Netherlands. The other climate and soil variables were sampled at $1 \mathrm{~Hz}$ and 30-minute averages were stored in a CR10X data logger (Campbell Scientific Inc., USA).

On the same main plot, weekly measurements of spectral reflectance were made using an 8-band radiometer (MSR87 MultiSpectral Radiometer, Cropscan Inc., USA) along 4 transects. The transects were $350 \mathrm{~m}$ long, with 20 sites per transect and 4 observations per site. Average reflectance and NDVI were obtained as a simple mean. The validity of the MSR87 reflectance measurements was tested by comparison between the MSR87 and a spectrometer with bandwidth of $4 \mathrm{~nm}$ (Personal Spectrometer II, Analytical Spectral Devices Inc., USA) and differences of less than $3 \%$ were found between the two sensors in the red and near-infrared bands. LAI measurements were carried out from anthesis to maturity stages using an AccuPAR sensor (Mansfield, UK) making one observation above and several below the wheat canopy to obtain the average light interception. The maximum LAI was found to be around 5 .

Observations were also collected for several other wheat fields around the experimental site and Figure 2A gives the location of these sites and illustrates the NDVI obtained at the beginning, middle and end of the agricultural season from Landsat-ETM+ images. Firstly, surface reflectances were collected with the same procedure (spatial transect, weekly time step) over a secondary plot where the wheat was sown 15 days before the main plot (i.e. November 25th). Secondly, planting and irrigation dates and grain yield were collected for 16 plots in an area of about $80 \mathrm{~km}^{2}$ in the vicinity of the main and secondary plots (Tab. I and Fig. 2). These data were supplied by the Yaqui Valley Farmers' Association and there were only 
Table I. Agricultural practices and yield for 16 wheat fields sampled around the experimental site. The field are numbered by increasing sowing date.

\begin{tabular}{|c|c|c|c|c|c|c|c|}
\hline \multirow{2}{*}{$\begin{array}{l}\text { Field } \\
\text { number }\end{array}$} & \multirow{2}{*}{$\begin{array}{c}\text { Sowing } \\
\text { date }\end{array}$} & \multirow{2}{*}{$\begin{array}{c}\text { Surface } \\
\text { (ha) }\end{array}$} & \multicolumn{3}{|c|}{ Irrigation dates } & \multicolumn{2}{|c|}{ Grain Yield $\left(\mathrm{g} \mathrm{m}^{-2}\right)$} \\
\hline & & & 1st Irrig. & 2nd Irrig. & 3rd Irrig. & observed & simulated \\
\hline 1 & Nov-14-99 & 25 & Jan-07-00 & Feb-07-00 & Mar-03-00 & 640 & 708 \\
\hline 2 & Nov-18-99 & 100 & dec-30-99 & $\mathrm{Feb}-03-00$ & $\mathrm{Feb}-28-00$ & 700 & 689 \\
\hline 3 & Nov-18-99 & 100 & Jan-03-00 & Feb-05-00 & Feb-29-00 & 700 & 701 \\
\hline 4 & Nov-19-99 & 50 & Jan-06-00 & Feb-10-00 & Mar-02-00 & 700 & 708 \\
\hline 5 & Nov-21-99 & 100 & Jan-06-00 & Feb-10-00 & Mar-17-00 & 700 & 701 \\
\hline 6 & Nov-24-99 & 25 & Jan-17-00 & Feb-21-00 & Mar-15-00 & 640 & 710 \\
\hline 7 & Nov-27-99 & 90 & Jan-25-00 & Feb-24-00 & Mar-16-00 & 650 & 693 \\
\hline 8 & Nov-29-99 & 46 & Jan-17-00 & Feb-19-00 & Mar-11-00 & 700 & 698 \\
\hline 9 & Dec-04-99 & 50 & Jan-26-00 & Feb-21-00 & Mar-10-00 & 630 & 692 \\
\hline 10 & Dec-08-99 & 25 & Jan-26-00 & $\mathrm{Feb}-22-00$ & Mar-17-00 & 650 & 680 \\
\hline 11 & Dec-09-99 & 46 & Jan-26-00 & $\mathrm{Feb}-26-00$ & Mar-21-00 & 700 & 680 \\
\hline 12 & Dec-09-99 & 40 & Jan-23-00 & Feb-20-00 & Mar-09-00 & 700 & 664 \\
\hline 13 & Dec-10-99 & 10 & $\mathrm{Feb}-04-00$ & Mar-05-00 & Mar-23-00 & 630 & 668 \\
\hline 14 & Dec-11-99 & 25 & Jan-30-00 & Feb-26-00 & Mar-20-00 & 650 & 680 \\
\hline 15 & Dec-17-99 & 16 & Feb-18-00 & Mar-09-00 & Mar-26-00 & 400 & 567 \\
\hline 16 & Dec-24-99 & 8 & Feb-13-00 & Mar-14-00 & Apr-03-00 & 500 & 523 \\
\hline
\end{tabular}

small differences in agricultural practices between the different fields. Typically the wheat is irrigated three times after sowing, with between 12 and $15 \mathrm{~cm}$ of water supplied for each irrigation. Nitrogen is generously applied by the farmers (from 100 to $300 \mathrm{~kg} \mathrm{ha}^{-1}$ ), so that no nitrogen restriction is present.

For the main plot, NDVI was computed from reflectances collected by the multispectral radiometer and combined with estimates of maximum LAI in order to estimate the seasonal dynamics of LAI by inversion of the following equation [2] (which is also used for reflectance observations collected on the secondary plot)

$$
\mathrm{NDVI}=\mathrm{NDVI}_{\infty}+\left(\mathrm{NDVI}_{\mathrm{s}}-\mathrm{NDVI}_{\infty}\right) \mathrm{e}^{-\mathrm{K}_{\mathrm{NDVI}} \mathrm{LAI}}
$$

where: $\mathrm{NDVI}_{\mathrm{s}}=0.14$ observed for bare soil, $\mathrm{NDVI}_{\infty}=0.94$ for an "infinite" LAI (corresponding to a maximum LAI of around 5, as derived from AccuPAR observations on the main plot) and $\mathrm{K}_{\mathrm{NDVI}}=1$ (value close to the ones found in [2] for wheat crops).

\subsection{Statistical analysis}

Three statistics were used for analysing the data: (1) the Mean Bias Error (MBE), which indicates the average deviation of the predicted values from the measured values; (2) the Root Mean Square Error (RMSE), which measures the variation of predicted values around observed values, and (3) the correlation coefficient $(\mathrm{R})$, which shows the degree to which two variables are linearly related.

\subsection{Description of the STICS model}

The STICS model [8-10] is a dynamic model with a daily time step, which simulates biomass, component yield, and water and nitrogen balance of several types of plants during their entire vegetative cycle. It uses the following input data: standard climate variables, management information, and soil and plant parameters. STICS has a modular design that allows the addition of new developments (e.g. ammoniac volatilisa- tion, symbiotic fixation and organic residues). At the moment, the modules available are: development, shoot growth, yield components, root growth, thermal environment, water and nitrogen balance and water, nitrate and heat transfer. The phenological development of the crop is largely controlled by canopy temperature, while the carbon balance drives biomass accumulation. The main state variable is leaf area index (LAI), which is controlled by phenology but regulated by water and nitrogen stress. This model has some differences with others in the development stages, because it represents growth stages rather than organ stages. These stages are: emergence, maximal acceleration of leaf growth, maximal leaf area index, grain filling, beginning of senescence, physiological maturity and the harvest stage. They correspond to change in the trophic or morphological strategy of the crop that influences the evolution of LAI or grain filling. One very important aspect of the STICS model is its ability to link with reflectance models [35] and support for data assimilation [4].

\subsection{Calibration of the STICS model version 5.0}

Simulations were performed with the climate variables measured on the main plot. Net radiation was calculated with the Brutsaert equation [8], and evapotranspiration was derived using the resistive approach [8]. After emergence, three irrigation events and no rain occurred during the experiment. The amount of nitrogen considered ensured that no stress occurred in the simulation period. This is reasonable given the fertilisation practices observed in the Yaqui valley. The soil had high clay and sand contents (clay: $48 \%$; loam: $14 \%$; sand: $38 \%$ ), with moisture characteristics given in Table II. The soil moisture is assumed to be $50 \%$ of readily available water at the sowing date using data from several experiments on clay soils, which range from 49 to $52 \%$ (F. Cabrera, INIFAP personal communication).

In order to calibrate the STICS model, we focused on LAI. Four parameters (Tab. III) strongly related to this variable were 
Table II. Initial soil parameters (FC = field capacity, WP = wilting point and $\mathrm{SD}=$ readily available water on sowing date).

\begin{tabular}{lcccc}
\hline $\begin{array}{l}\text { Layer } \\
(\mathrm{cm})\end{array}$ & \multicolumn{3}{c}{ Soil Moisture $(\mathrm{kg} / \mathrm{kg}) \times 100$} & $\begin{array}{c}\text { Bulk } \\
\text { density }\end{array}$ \\
\cline { 2 - 4 } & FC & WP & SD & \\
\hline $0-10$ & 35 & 18 & 27 & 1.35 \\
$10-14$ & 35 & 18 & 27 & 1.35 \\
$40-70$ & 35 & 17 & 26 & 1.43 \\
$70-100$ & 35 & 17 & 26 & 1.43 \\
$100-160$ & 35 & 17 & 27 & 1.43 \\
\hline
\end{tabular}

Table III. Plant parameters modified during the calibration of STICS.

\begin{tabular}{lccc}
\hline Parameter & $\begin{array}{c}\text { Process regulated } \\
\text { by the parameter }\end{array}$ & $\begin{array}{c}\text { Default } \\
\text { value }\end{array}$ & $\begin{array}{c}\text { Value after } \\
\text { calibration }\end{array}$ \\
\hline Dlaimax & setting up of LAI & 0.00032 & 0.00011 \\
Laicomp & inter-plant competition & 0.304 & 0.094 \\
Adens & stem density & -0.6 & -0.3 \\
DurvieL & life duration of leaves & 0.8 & 1 \\
\hline
\end{tabular}

selected based on the results and sensitivity analysis found in $[9,4,31]$. These parameters are associated with all the processes that control the temporal evolution of LAI (Tab. III), and several simulations were performed in order to understand the effect of each one of them. The Simplex algorithm included in the STICS model has helped us to determine some of these parameters, but no particular method was used for optimisation: the parameters and the dates of phenological stages (forcing option) were varied until the time series of LAI simulated by STICS and those observed on the main plot (i.e. estimated from NDVI by equation (1) matched fairly well. The result of this optimisation procedure is shown in Figure 3; the best simulation leads to statistics consistent with those found in [16] $(\mathrm{MBE}=-0.04, \mathrm{RMSE}=0.25$ and $\mathrm{R}=0.99)$.

Once the LAI seasonal dynamics have been optimised (Fig. 3), the simulation for the main plot can be used to test the other outputs of the model against experimental data. The same simulation provides parameters (last column of Tab. III) and the thermal duration for each phenological stage (not shown here). From now on, we assume that the STICS model can be run without additional information except the agricultural practices (sowing and irrigation dates). Additional simulation for the secondary plot - where field reflectance measurements are also available - allowed an additional validation for LAI, while the data collected for the remaining 16 fields (Tab. I) were used to evaluate the performance of the model in terms of yield prediction. It is important to note that all the simulations are based on the same set of parameters and initial soil conditions (Tabs. II and III).

\section{RESULTS AND DISCUSION}

In this section, the results are presented as they relate to local and then regional scale analysis.

\subsection{Local scale validation}

On the local scale, the model is evaluated against the experimental data set obtained on the main (surface temperature, net

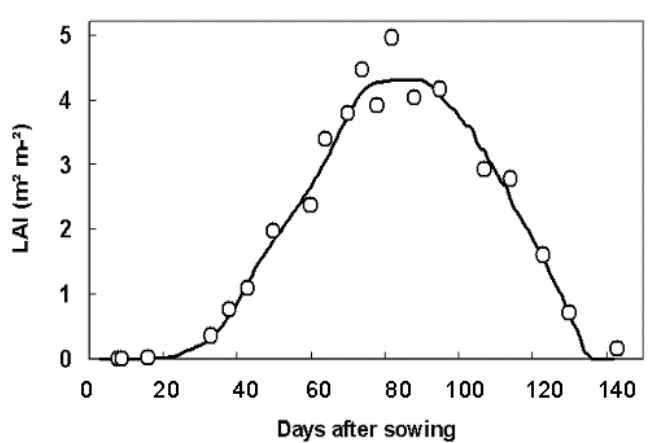

Figure 3. Leaf area index simulated by STICS (after calibration, line) and obtained from the NDVI measured at surface (Eq. (1) applied to multispectral radiometer measurements, symbols) on the main plot.

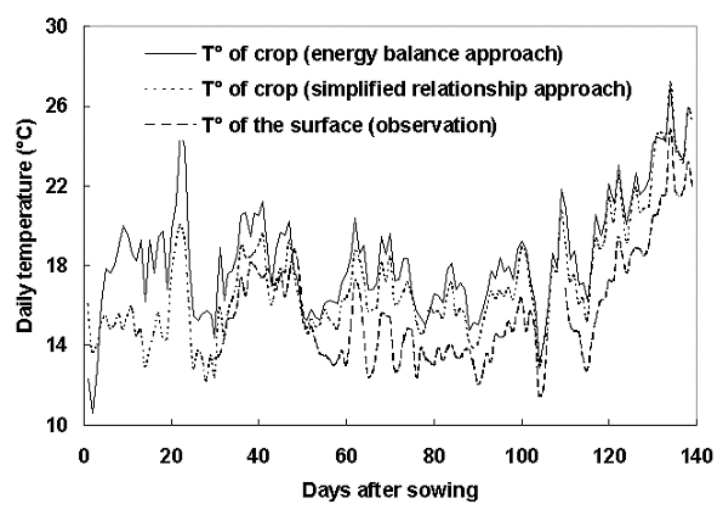

Figure 4. Daily evolution of crop temperature (simulated by STICS with the two possible approaches) and surface temperature (observed on the main plot using an infrared thermoradiometer).

radiation, evapotranspiration and soil moisture) and secondary (LAI) plots.

\subsubsection{Surface temperature}

The daily crop temperature (TCULT) is an important variable in STICS, which is used (iteratively) in the calculation of plant development, evapotranspiration and net radiation. The daily value is computed by STICS as the mean of the maximum (TCULTMAX) and minimum (TCULTMIN) values and two methods are provided to calculate these. The "surface energy balance" approach is based on two instantaneous calculations made at the time of maximum and minimum air temperature. The "simplified relationship" uses a relationship between maximum surface temperature and daily evaporation including surface roughness [33] and assumes that TCULTMIN is equal to the measured minimum air temperature. We tested both methods against the daily average surface temperature measured with the infrared thermoradiometer. A systematic overestimation by about $2.5^{\circ} \mathrm{C}$ was observed for both approaches (Fig. 4), with greater overestimation for the energy balance method $\left(\mathrm{MBE}=2.94\right.$ and $2.02{ }^{\circ} \mathrm{C}, \mathrm{RMSE}=3.39$ and $2.56^{\circ} \mathrm{C}$, and $\mathrm{R}=$ 0.78 and 0.84 for the energy balance and simplified relationship approaches, respectively). Since crop temperature is better simulated by the simplified relationship, this approach was adopted. 
The overestimation visible in Figure 4 is surprising, as the model simulates the crop foliage temperature while the infrared thermometer measures a composite of canopy and soil temperatures, with soil temperature generally higher than that of the foliage. However, the overestimation is also significant when the vegetation coverage is maximal (in the middle of the season) and the radiometer mainly observes the foliage. This component of the model needs to be studied further.

\subsubsection{Net radiation}

Net radiation results from the balance between incoming and outgoing short-wave and long-wave radiations at or close to the surface. It represents the energy available at the surface for other processes [1]. During full-cover stages it can be more than $90 \%$ of the energy available at crop level and, provided water is available in the soil, most of this energy is used for transpiration. In the calculation of net radiation, the crop temperature is a significant term.

Figure 5 shows the comparison between observed and simulated components of net radiation. The overestimation of crop temperature (previously discussed in Fig. 4) results in considerable dispersion and underestimation of net long-wave radiation $\left(\mathrm{MBE}=-0.9 \mathrm{MJ} \mathrm{m}^{-2} \mathrm{~d}^{-1}, \mathrm{RMSE}=1.97 \mathrm{MJ} \mathrm{m}^{-2} \mathrm{~d}^{-1}\right.$ and $\mathrm{R}=0.61$ in Fig. $5 \mathrm{~A}$ ). Simulated net short-wave radiation closely matches observations $\left(\mathrm{MBE}=-0.05 \mathrm{MJ} \mathrm{m}^{-2} \mathrm{~d}^{-1}, \mathrm{RMSE}=\right.$ $0.39 \mathrm{MJ} \mathrm{m}^{-2} \mathrm{~d}^{-1}$ and $\mathrm{R}=0.99$ in Fig. 5B), with better results than those reported in [34]. Consequently, the agreement between simulated and observed net radiation appears acceptable $\left(\mathrm{MBE}=-0.86 \mathrm{MJ} \mathrm{m}^{-2} \mathrm{~d}^{-1}, \mathrm{RMSE}=1.29 \mathrm{MJ} \mathrm{m}^{-2} \mathrm{~d}^{-1}\right.$ and $\mathrm{R}=0.96$ in Fig. 5C).

\subsubsection{Soil moisture}

Soil moisture is another important parameter simulated by STICS. It has a significant effect on soil evaporation, plant transpiration and crop temperature. Figure 6 shows the simulated and observed water content at two soil depths. After each irrigation, both simulated and observed values quickly reach field capacity. Between irrigation events, important differences can be noted between simulation and observation. Firstly, the simulated and observed soil moisture of the deepest layer do not compare well during the initial drying phase. This is probably due to a large underestimation of the initial value of soil moisture chosen for the simulation. Secondly, the evolution of the top layer moisture appears somewhat strange, with maximum depletion at the end of the drying phases. The most likely explanation is errors in the measurements due to loss of good contact between the soil moisture probes and the soil, since the soil has high clay content and cracks as it dries. Thirdly, four peaks are observed on the experimental data, while we considered three irrigation events in the simulation. Water supply has probably been incorrectly reported during the end of the experiment, as two irrigation events appear to occur within a short period (10 days around day 100, Fig. 6). Despite these significant differences, the general level and trend in soil moisture appear to be correctly modelled $(\mathrm{MBE}=0.020$ and $-0.032 \mathrm{~kg} / \mathrm{kg}, \mathrm{RMSE}=0.063$ and $0.045 \mathrm{~kg} / \mathrm{kg}$, and $\mathrm{R}=0.73$ and 0.67 for the surface and deep layer, respectively, in Fig. 6).
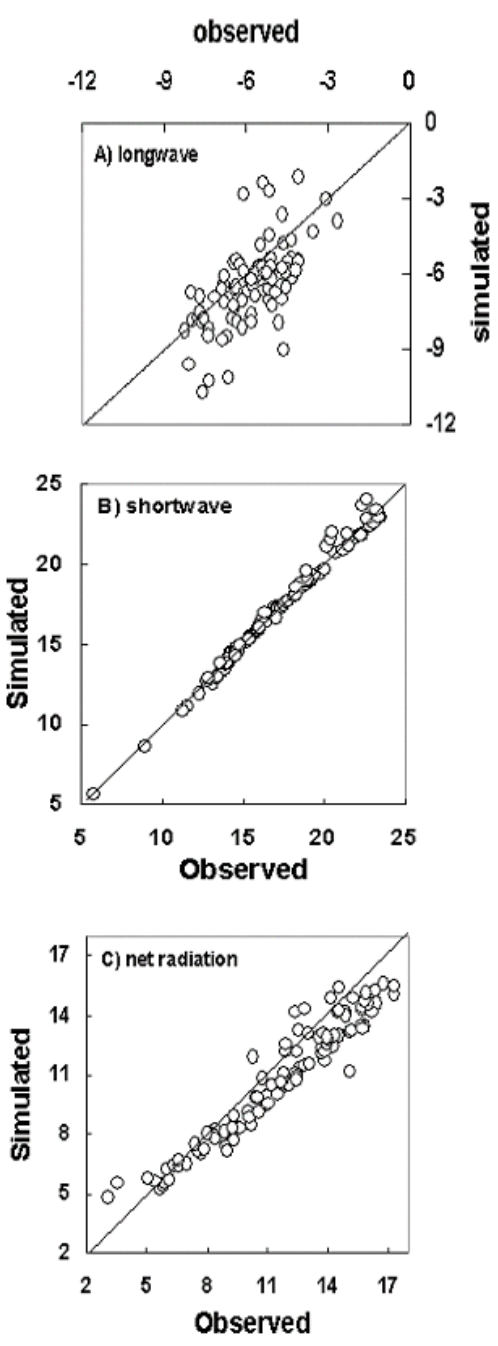

Figure 5. Components of the radiative budget on the main plot (in $\mathrm{MJ} \mathrm{m}^{-2} \mathrm{~d}^{-1}$ ): (A) Net long-wave radiation, (B) Net shortwave radiation and $(\mathrm{C})$ Net (all-wave) radiation.

\subsubsection{Evapotranspiration}

Water stress affects the crop during all the growth stages, reducing the forage and/or grain yield. Yield is very sensitive to moisture deficit in the period from flowering to grain filling. The ability of the STICS model to correctly simulate soil evaporation and plant transpiration is thus important, especially in a semiarid environment.

Measured and simulated evapotranspiration (ET) are compared in Figure 7. The average level and seasonality of ET appear to be well reproduced by the model $(\mathrm{MBE}=-0.21 \mathrm{~mm}$, $\mathrm{RMSE}=1.03 \mathrm{~mm}$ and $\mathrm{R}=0.74)$, but large differences occurred around irrigation events (Fig. 7):

- At the beginning of the period of observation (10-day period before the first irrigation), the model underestimates ET. We have assumed that this is a consequence of the underestimation of the initial soil moisture of deep layers (see Fig. 6). 


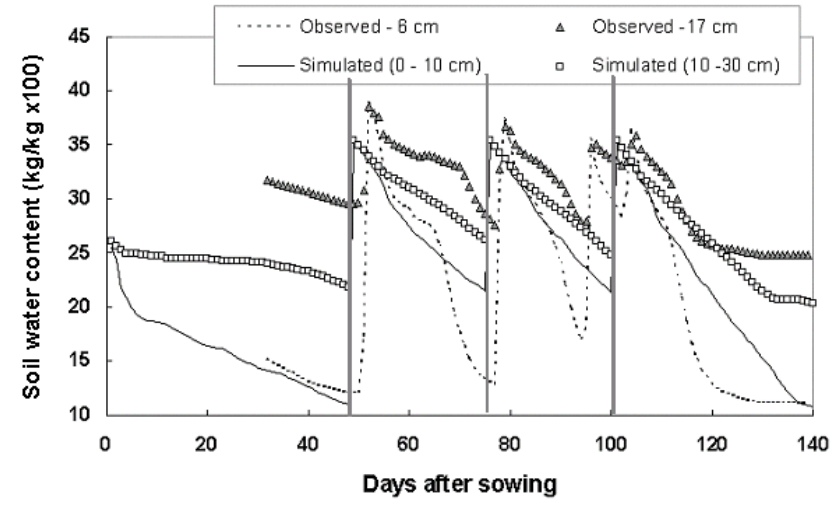

Figure 6. Daily evolution of soil water content for two different layers (main plot). The three irrigation events, with $150 \mathrm{~mm}$ of water supplied each, are highlighted by the bars plotted at the dates of supply used as input in the simulation.

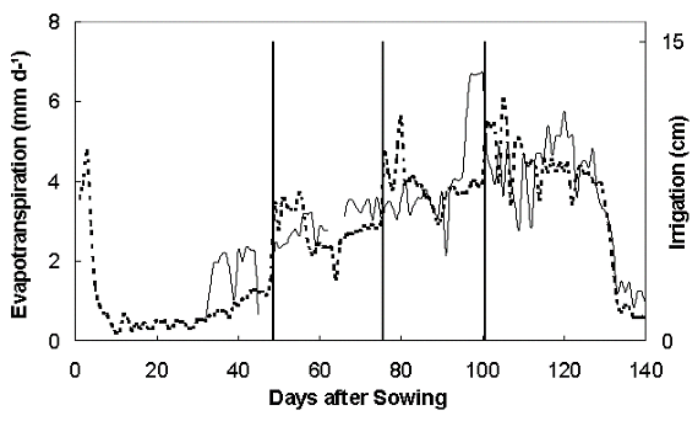

Figure 7. Daily evolution of simulated (dotted line) and observed (full line) evapotranspiration (main plot). The three irrigation events, with $150 \mathrm{~mm}$ of water supplied each, are highlighted by the bars plotted on the dates of supply used as input in the simulation.

However, both the simulation and observation shows that the crop is not stressed between the sowing date and the first irrigation event. This probably arises from an underestimation of LAI (and thus transpiration) at this period during the simulation.

- After the first and second irrigation events, the simulated ET increases (because of a high level of soil evaporation) but the measured ET does not. The same behaviour was observed in a previous study in the Yaqui Valley [17]. It is due to the fact that the foliage completely covers the space between rows at this time in the wheat development, resulting in very low soil evaporation, whereas the model simulates evaporation peaks.

- During the final irrigation events, both measured and simulated ET increase. At this time, the wheat cover has decreased and there is a significant soil evaporation component to ET. Moreover, a delay of around one week can be observed between the modelled and observed increase in ET. Better information about the conditions for this irrigation would be needed in order to reach clear conclusions about the accuracy

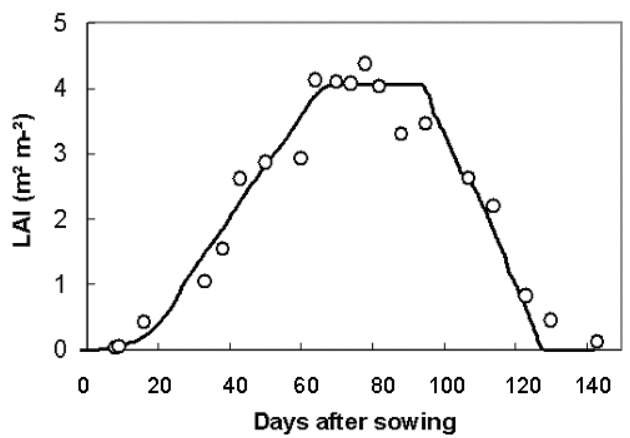

Figure 8. Same as Figure 3 for the secondary plot.

of simulated ET (as well as soil moisture, see Fig. 6) at the end of the experiment.

From this analysis, it appears that the STICS model generally simulates the evolution of ET very well, but it does not work correctly for irrigation events when the vegetation coverage is nearly total.

\subsubsection{Leaf area index}

Reflectance values acquired in the red and near-infrared bands were used to calculate NDVI and then to deduce the LAI by equation (1). A comparison of the estimates for LAI with those simulated by STICS on the secondary plot is shown in Figure 8 . The simulated LAI shows excellent agreement with estimation from the NDVI $(\mathrm{MBE}=0.02, \mathrm{RMSE}=0.3$ and $\mathrm{R}=$ 0.98 ). This result is comparable with that obtained on the main plot (see Fig. 3), on which the model was calibrated. These good results were expected, since the major difference between the main and secondary plots is a short delay (15 days) of the sowing date.

\subsection{Yield estimation and NDVI analysis on a regional scale}

Table I compares prediction and observation of yield on 16 fields with contrasting sowing and irrigation dates. The yield data were collected by the local farmers' association and no technical details were available on the protocol for these observations, so that their reliability is somewhat questionable. Therefore the difference between these yield values and those simulated by STICS may be due, at least in part, to errors in these data.

In Table I, most of the fields record similar yields, between 600 and $700 \mathrm{~g} \mathrm{~m}^{-2}$. This is a consequence of the homogeneity in agricultural practices in the Yaqui Valley. Most farmers apply a large amount of fertilisers, and the irrigation system allows water to be supplied according to a regular calendar (on average 50, 80 and 100 days separate the sowing date from the 1st, 2nd and 3rd irrigation events, respectively, with a standard deviation of around 6 days). This ensures that plants do no suffer severe stress. This assumption is confirmed by predictions, with yields around the observed values and no reduction because of nitrogen or water deficit (stress indices are always close to 1 , whatever the period and the simulation). The two 


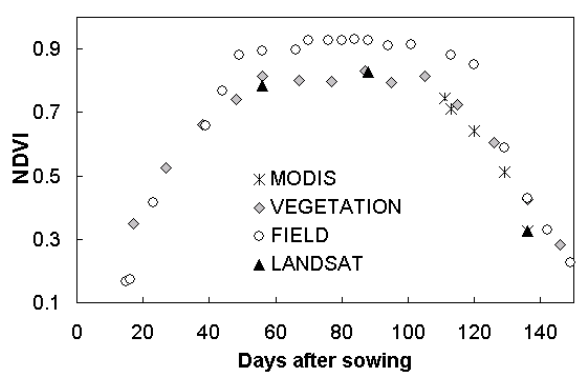

Figure 9. NDVI evolution from different satellite platforms and field measurements on the main plot.

fields that were sown the latest (end of December, see the fields numbered 15 and 16 in Tab. I) show the lowest yields (400 and $500 \mathrm{~g} \mathrm{~m}^{-2}$ ). STICS reproduces this trend (decrease in yield of around $150 \mathrm{~g} \mathrm{~m}^{-2}$ ) because of delayed growth and the negative effect of high temperatures during maturity (with shorter phenological stages). This is consistent with the statements found in $[6,15]$.

As a result, there is reasonable agreement between simulated and observed yield values $\left(\mathrm{MBE}=29.5 \mathrm{~g} \mathrm{~m}^{-2}, \mathrm{RMSE}=\right.$ $55 \mathrm{~g} \mathrm{~m}^{-2}$ and $\mathrm{R}=0.84 \mathrm{~g} \mathrm{~m}^{-2}$ in Tab. I), with errors comparable with other studies in the same area [25]. This indicates the robustness of the model, which predicts values consistent with observations associated with different agricultural practices after calibration using the data collected on only one plot.

Figure 9 shows NDVI evolution for the main plot as obtained from satellite data (Terra-MODIS, Landsat-ETM+ and VEGETATION) together with the corresponding field data (multispectral radiometer measurements). The seasonal variation of NDVI is apparent in all these remotely-sensed data. However, the maximum value of NDVI (for the mature crop at full cover) is about $10 \%$ less for the satellite data compared with groundbased measurements. This is a consequence of the sensor type and depends on its spatial resolution and mixing effect, as well as data processing. The field and VEGETATION data, acquired on a weekly or 10-day basis, show the same seasonality: growth, maturity and senescence stages are clearly identified. The five MODIS scenes show good agreement with the other data for the period from maturity to senescence.

An apparent limitation concerning the use of remotelysensed data is confirmed in Figure 9: the NDVI saturates at the full development stage [21], so that the LAI may continue to increase but with little or no increase in the NDVI. Consequently, accurate estimates of LAI from satellite data throughout the agricultural season would require: (1) the exact knowledge of the maximum LAI value estimates on the spatial scale of the sensor, and (2) a sound data processing scheme for calibration, atmospheric correction, normalisation between various sun-target-sensor geometries and compositing of satellite data. These two requirements are difficult to meet. However, it has been suggested that inaccurate knowledge of LAI only becomes important when it is small or is being used to estimate canopy $\mathrm{N}$ content [22], so this problem might not be so serious.
Table IV. Statistics of NDVI values observed at high and low spatial resolution $($ std $=$ standard deviation associated with the NDVI spatial mean of ETM+ data on each field or to the value of the VEGETATION pixel that includes the field, see Fig. 2).

\begin{tabular}{lccccc}
\hline Date & \multicolumn{2}{c}{ LandSat - ETM +} & & \multicolumn{2}{c}{ SPOT-VEGETATION } \\
\cline { 2 - 3 } \cline { 5 - 6 } & mean & std & & mean & std \\
\hline January 25 & 0.70 & 0.08 & & 0.73 & 0.05 \\
February 26 & 0.78 & 0.04 & & 0.86 & 0.02 \\
April 14 & 0.34 & 0.12 & & 0.47 & 0.07 \\
\hline
\end{tabular}

In order to illustrate the effect of spatial resolution, Table IV presents the statistics obtained on the fields of interest from ETM+ and VEGETATION observations. As expected, the variation in NDVI values between the fields is larger at high than at low spatial resolution, by around a factor 2 . Large spatial variation of NDVI on a 30-m scale (ETM+) appears between and even within fields (see Fig. 2, especially on the first and the last dates). In contrast, the standard deviation associated with the spatial variation in NDVI derived on a 1-km scale is low (beginning and end of the agricultural season) to very low (middle of the season). Given the size of the fields of interest (Tab. I), the potential of the VEGETATION system to track the variability of crop development within each irrigation block appears limited. This limitation is reinforced by the fact that 10-day composite data are obtained from the MVC technique, which tends to artificially smooth out the spatial variability of NDVI because misregistered pixels can be selected if they display a higher NDVI than their neighbourhood [14].

\section{CONCLUSION}

An experiment was carried out to validate the STICS model for wheat in a semiarid environment in Northwest Mexico. First, STICS was calibrated to optimise the LAI simulated by the model for a large wheat field, by comparison with values retrieved from the NDVI measured at the surface using a multispectral field radiometer. The calibration site was carefully monitored throughout the season and measurements of surface temperature, net radiation, evapotranspiration and soil moisture were used for validation. The simulated crop temperature was found to be overestimated by $2-3{ }^{\circ} \mathrm{C}$ and the simplified relationship performed somewhat better than the energy balance approach. Crop temperature is the principal variable, which drives crop phenology, so that this overestimation has an important impact on net radiation (through long-wave net radiation) and evapotranspiration. The soil moisture is simulated correctly in the wetting and drying phases. However, important differences were observed between simulated and measured soil moisture at the end of the drying phases, which are probably due to errors in the observations.

On a larger scale, the potential for using satellite data was studied over the calibration site. Values of NDVI derived from different satellite platforms showed the correct seasonal behaviour and the onset of growth and senescent stages could be easily identified. However, there were significant (10\%) differences between the maximum NDVI from satellite data and that obtained 
in the field. Furthermore, the observed spatial variation in NDVI decreased (i.e. smoothing) as the pixels size increased, while images with high spatial resolution were not available with sufficient frequency. This emphasises the need for satellite remote-sensing systems with both high spatial and temporal resolution, as well as the use of sound-processing schemes in order to reduce the various causes of errors associated with satellite data.

After validation on the local scale, the model was run for 16 fields where the sowing and irrigation dates were known. The grain yields predicted by the model have comparable errors with those obtained in previous studies [25]. Thus the STICS model, after calibration over one wheat field using estimates of LAI obtained from ground reflectances, was able to achieve good prediction of grain yield over other wheat fields in the region.

Acknowledgments: This work was done as part of the SALSA project for agricultural areas with support from the Consejo Nacional de Ciencia y Tecnología (CONACYT) under Project 29340T. The study was conducted within the framework of the IRD/Sud-Med project, with support from the European Union 5th Framework INCO-MED Programme through the following projects: WATERMED ("WATer use Efficiency in natural vegetation and agricultural areas by Remote sensing in the MEDiterranean basin") with the University of Valencia as Principal Investigator (see http://www.uv.es/ucg/watermed) and IRRIMED ('Improved management tools for water-limited irrigation: combining ground and satellite information through models') with the CESBIO as Principal Investigator. Finally, we would like to thank the two anonymous reviewers for their comments that substantially improved the paper.

\section{REFERENCES}

[1] Arya S.P., Introduction to micrometeorology, Academic Press, 2001, $420 \mathrm{p}$.

[2] Asrar G., Fuchs M., Kanemasu E.T., Hatfield J.L., Estimating absorbed photosynthetic radiation and leaf area index from spectral reflectance in wheat, Agron. J. 76 (1984) 300-306.

[3] Baret F., Guyot G., Major D.J., Crop biomass evaluation using radiometric measurement, Photogrammetria 43 (1989) 241-256.

[4] Baret F., Weiss M., Troufleau D., Asimilation of multi temporalspectral-directional reflectance data in a NPP model: a case study and comparison of sampling schemes for different sensors, Final Report ESA, Feb. 2002, pp. 1-29.

[5] Bastiaanssen W.G.M., Remote sensing in water resources management: the state of the art, IWMI (1998) 1-118.

[6] Benbella M., Paulsen G.M., Efficacy of treatments for delaying senescence of wheat leaves: II. Senescence and grain yield under field conditions, Agron. J. 90 (1998) 332-337.

[7] Boote K.J., Jones J.W., Pickering N.B., Potential use and limitations of crop models, Agron. J. 88 (1996) 704-716.

[8] Brisson N., Mary B., Ripoche D., Jeuffroy M.H., Ruget F., Nicoullaud B., Gate P., Devienne-Baret F., Antonioletti R., Durr C., Richard G., Beaudoin N., Recous S., Tayot X., Plenet D., Cellier P., Machet J.M., Meynard J.M., Delécolle R., STICS: a generic model for the simulation of crops and their water and nitrogen balances. I. Theory and parameterisation applied to wheat and corn, Agronomie 18 (1998) 311-346.

[9] Brisson N., Ruget F., Gate F., Lorgeou J., Nicoullard B., Tayot X., Plenet D., Jeuffroy M.-H., Brouthier A., Ripoche S., May B., Justed E., STICS: a generic model for he simulation of crops and their water and nitrogen balances. II. Model validation for wheat and maize, Agronomie 22 (2002) 69-92.
[10] Brisson N., Gary C., Justes E., Roche R., Mary B., Ripoche D., Zimmer D., Sierra J., Bertuzzi P., Burger P., Bussière F., Cabidoche Y.M., Cellier P., Debaeke P., Gaudillère J.P., Hénault C., Maraux F., Seguin B., Sinoquet H., An overview of the crop model STICS, Eur. J. Agron. 18 (2003) 300-306.

[11] Choudhury B.J., Ahmed N.U., Idso S.B., Reginato R.J., Daughtry C.S.T., Relations between evaporation coefficients and vegetation indices studied by model simulations, Remote Sens. Environ. 50 (1994) 1-17.

[12] Dedieu G., Cabot F., Chehbouni A., Duchemin B., Maisongrande P., Boulet G., Pellenq J., RHEA: a micro-satellite mission for the study and modelling of land surfaces through assimilation techniques, 23th International Geosciences And Remote Sensing Symposium (IGARSS), Toulouse (France), July 21-25, 2003.

[13] Duchemin B., Goubier J., Courrier G., Monitoring phenological key-stages and cycle duration of temperate deciduous forest ecosystems with NOAA-AVHRR data, Remote Sens. Environ. 67 (1999) 51-67.

[14] Duchemin B., Berthelot B., Dedieu G., Leroy M., Maisongrande P., Normalisation of directional effects in 10-day global syntheses derived from VEGETATION/SPOT: II. Validation of an operational method on actual data sets, Remote Sens. Environ. 81 (2002) $101-113$.

[15] Ehdaie B., Waines J.G., Sowing date and nitrogen rate effects on dry mater and nitrogen partitioning in bread and durum wheat, Field Crop Res. 73 (2001) 47-61.

[16] Friedl M.A., McIver D.K., Hodges J.C.F., Zhang X.Y., Muchoney D., Strahler A.H., Woodcock C.E., Gopal S., Schneider A., Cooper A., Baccini A., Gao F., Chaaf C., Global land cover mapping from MODIS: algorithms and early results, Remote Sens. Environ. 83 (2002) 297-302.

[17] Garatuza-Payan J., Shuttleworth W.J., Encinas D., McNeil D.D., Stewart J.B., De Bruin H.A.R., Watts C.J., Measurement and modelling evaporation for irrigated crops in northwest Mexico, Hydrol. Process. 12 (1998) 1397-1418.

[18] Hansen J.W., Jones J.W., Scaling-up crop models for climate variability, Agric. Ecosyst. 62 (2000) 43-72.

[19] Hoogenboom G.J., Jones J.W., Wilkens P.W., Batchelor W.D., Bowen W.T., Hunt L.A., Pickering N.B., Singh U., Godwin D.C., Baer B., Boote K.J., Ritchie J.T., White J.W., Crop models, in: Tsuji G.Y., Uehara G., Balas S. (Eds.), DSSAT Version 32, University of Hawaii, Honolulu, HI (1994), pp. 95-244.

[20] http://daac.gsfc.nasa.gov/data/datebase/MODIS/01_level_1.

[21] Huete A., Didan K., Miura T., Rodriguez E.P., Gao X., Ferreira L.G., Overview of the radiometric and biophysical performance of the MODIS vegetation indices, Remote Sens. Environ. 83 (2002) 195-213.

[22] Jamieson P.D., Semenov M.A. Brooking I.R., Francis G.S., Sirius: a mechanistic model of wheat response to environmental variation, Eur. J. Agron. 8 (1998) 161-179.

[23] Knyazikhin Y., Martonchik J.V., Myneni R.B., Diner D.J., Running W., Estimation of vegetation canopy leaf area index and fraction of absorbed photosynthetically active radiation from atmospherecorrected MISR data, J. Geophys. Res. 104 (D24) (1998) 3223932256.

[24] Lobell D.B., Asner G.P., Ortiz-Monasterio J.I., Benning T.L., Remote sensing of regional crop production in the Yaqui Valley, Mexico: estimates and uncertainties, Agric. Ecosyst. Environ. 94 (2003) 205-220.

[25] Lobell D.B., Ortiz-Monasterio J.I., Lee Adams C., Asner G.P., Soil, climate, and management impacts on regional wheat productivity in Mexico from remote sensing, Agric. For. Meteorol. 114 (2002) 31-41. 
[26] Maisongrande P., Duchemin B., Dedieu G., VEGETATION/ SPOT: An Operational Mission for the Earth Monitoring Presentation of New Standard Products, Int. J. Remote Sens., accepted.

[27] McCown R.L., Hammer G.L., Hargreaves N.G., Holzworth D.P., Freebairn D.M., APSIM: A novel Software system for model development. Model testing and simulation in agricultural system research, Agric. Syst. 50 (1996) 225-271.

[28] Myneni R.B., Hoffman S., Knyazikhin Y., Privette J.L., Glassy J., Tian J., Wang Y., Song X., Zhang Y., Smith G.R., Lotsch A., Friedl M., Morisette J.T., Votava P., Nemani R.R., Running S.W., Global products of vegetation leaf area and fraction absorbed PAR from year one of MODIS data, Remote Sens. Environ. 83 (2002) 214-231.

[29] Petitcolin F., Vermote E., Land surface reflectance, emissivity and temperature from MODIS middle and thermal infrared data, Remote Sens. Environ. 83 (2002) 112-134.

[30] Ritchie J.T., The CERES-Maize model, in: CERES-Maize: Simulation model of maize growth and development, Jones C.A., Kiniry J.R. (Eds.), Texas A M University Press, college station, Tx., 1986, pp. 3-6.
[31] Ruget F., Brisson N., Delecolle R., Faivre R., Sensibility analysis of a crop simulation model, STICS, in order to choose the main parameters to be estimated, Agronomie 22 (2002) 133-158.

[32] Sakthivadivel R., Triruvengadachari S., Amerasinghe U., Bastiaanssen W.G.M., Performance evaluation of the Bhakra Irrigation system, India, using remote sensing and GIS techniques, Research report 28, IWMI, 1999, Colombo, Sri Lanka.

[33] Seguin B., Itier B., Using midday surface temperature to estimate daily evaporation from satellite thermal IR data, Int. J. Remote Sens. 4 (1983) 371-383.

[34] Twine T.E., Kustas W.P., Norman J.M., Cook D.R., Houser P.R., Meyers P., Preuger J.H., Starks P.J., Wesely M.L., Correcting eddy-covariance flux underestimates over a grassland, Agric. For. Meteorol. 103 (2000) 279-300.

[35] Weiss M., Troufleau D., Baret F., Chauki H., Prevot L., Olioso A., Bruguier N., Brisson N., Coupling canopy functioning and radiative transfer models for remote sensing data assimilation, Agric. For. Meteorol. 108 (2001) 113-128.

[36] Zhang X., Friedl M.A., Schaaf C.B., Strahler A.H., Hodges J.C.F., Gao F., Reed B.C., Huete A., Monitoring vegetation phenology using MODIS, Remote Sens. Environ. 84 (2003) 471-475. 